\title{
Peroxisomal Fatty Acid $\beta$-Oxidation in Relation to the Accumulation of Very Long Chain Fatty Acids in Cultured Skin Fibroblasts from Patients with Zellweger Syndrome and Other Peroxisomal Disorders
}

\author{
Ronald J. A. Wanders," Carlo W. T. van Roermund," Michel J. A. van Wijland," Ruud B. H. Schutgens," Judith Heikoop," \\ Henk van den Bosch, ${ }^{\ddagger}$ André W. Schram, and Joseph M. Tager \\ *Department of Pediatrics, University Hospital Amsterdam, 1105 AZ Amsterdam, ${ }^{\ddagger}$ Laboratory of Biochemistry, \\ State University Utrecht, 3584 CH Utrecht, ${ }^{\S}$ Laboratory of Biochemistry, University of Amsterdam, \\ 1000 HD Amsterdam, The Netherlands
}

\section{Abstract}

The peroxisomal oxidation of the long chain fatty acid palmitate (C16:0) and the very long chain fatty acids lignocerate (C24:0) and cerotate (C26:0) was studied in freshly prepared homogenates of cultured skin fibroblasts from control individuals and patients with peroxisomal disorders. The peroxisomal oxidation of the fatty acids is almost completely dependent on the addition of ATP, coenzyme $\mathrm{A}(\mathrm{CoA}), \mathrm{Mg}^{2+}$ and $\mathrm{NAD}^{+}$. However, the dependency of the oxidation of palmitate on the concentration of the cofactors differs markedly from that of the oxidation of lignocerate and cerotate.

The peroxisomal oxidation of all three fatty acid substrates is markedly deficient in fibroblasts from patients with the Zellweger syndrome, the neonatal form of adrenoleukodystrophy and the infantile form of Refsum disease, in accordance with the deficiency of peroxisomes in these patients. In fibroblasts from patients with X-linked adrenoleukodystrophy the peroxisomal oxidation of lignocerate and cerotate is impaired, but not that of palmitate. Competition experiments indicate that in fibroblasts, as in rat liver, distinct enzyme systems are responsible for the oxidation of palmitate on the one hand and lignocerate and cerotate on the other hand. Fractionation studies indicate that in rat liver activation of cerotate and lignocerate to cerotoyl-CoA and lignoceroyl-CoA, respectively, occurs in two subcellular fractions, the endoplasmic reticulum and the peroxisomes but not in the mitochondria. In homogenates of fibroblasts from patients lacking peroxisomes there is a small (25\%) but significant deficiency of the ability to activate very long chain fatty acids. This deficient activity of very long chain fatty acyl-CoA synthetase is also observed in fibroblast homogenates from patients with X-linked adrenoleukodystrophy. We conclude that $X$-linked adrenoleukodystrophy is caused by a deficiency of peroxisomal very long chain fatty acyl-CoA synthetase.

\section{Introduction}

Although peroxisomes were long believed to have only a minor function in mammalian metabolism, it has become

\footnotetext{
Address reprint requests to $\mathrm{Dr}$. Wanders.

Received for publication 7 April 1987 and in revised form 8 July 1987
}

J. Clin. Invest.

(C) The American Society for Clinical Investigation, Inc.

$0021-9738 / 87 / 12 / 1778 / 06 \quad \$ 2.00$

Volume 80, December 1987, 1778-1783 clear in recent years that these organelles play an important role in a number of metabolic pathways including fatty acid $\beta$-oxidation, ether-phospholipid biosynthesis and bile acid biosynthesis (for reviews see 1-4). The importance of peroxisomes in man can be gauged from the existence of a group of genetic diseases caused by an impairment in one or more peroxisomal functions (5-8). Goldfischer and co-workers (9) were the first to observe that morphologically distinguishable peroxisomes are absent in liver and kidney tubules from patients with the cerebro-hepato-renal (Zellweger) syndrome, the prototype of this newly recognized group of peroxisomal disorders.

In 1976 Lazarow and de Duve (10) reported that mammalian peroxisomes are capable of oxidizing fatty acyl-coenzyme A $(\mathrm{CoA})^{1}$ esters. Subsequent studies revealed that fatty acyl$\operatorname{CoA} \beta$-oxidation in peroxisomes occurs via a true $\beta$-oxidation system involving sequential steps of oxidation, hydration, dehydrogenation, and thiolytic cleavage (11). Rather than being a duplication of the mitochondrial $\beta$-oxidation system, mammalian peroxisomes seem specially equipped to catalyze the chain-shortening of monounsaturated long chain fatty acids (12) and saturated very long chain fatty acids (13).

Before fatty acids can undergo further metabolism, activation to the corresponding fatty acyl-CoA esters must occur (14). Several acyl-CoA synthetases are known to be present in mammalian cells $(14,15)$ including long chain acyl-CoA synthetase (acid:CoA ligase (AMP-forming), EC 6.2.1.3; also known as palmitoyl-CoA synthetase), which has been found to be localized in mitochondria and microsomes (for reviews see $14,15)$ as well as in peroxisomes (16-19). Evidence has recently been brought forward (20) indicating that in rat brain microsomes the enzyme catalyzing the activation of the very long chain fatty acid tetracosanoic acid (lignoceric acid, C24:0) is different from the corresponding enzyme responsible for the activation of hexadecanoic acid (palmitic acid, C16:0). We have recently shown that this is also the case in rat liver homogenates (21).

Very long chain fatty acids accumulate in patients with the cerebro-hepato-renal (Zellweger) syndrome, in which peroxisomes are absent and peroxisomal functions are impaired (5-8). This finding stresses the importance of peroxisomes in the oxidation of very long chain fatty acids. Accumulation of very long chain fatty acids is also found in patients with the $\mathrm{X}$-linked form of adrenoleukodystrophy, a disease in which other peroxisomal functions are not impaired (5-8). Hashmi et al. (22) have suggested that the impairment in peroxisomal $\beta$-oxidation in this disease is due to a deficiency of the peroxi-

1. Abbreviations used in this paper: CoA, coenzyme A; MOPS, morpholinopropane sulphonic acid. 
somal enzyme responsible for the activation of very long chain fatty acids.

The availability of cultured skin fibroblasts from patients with mutations leading to peroxisomal disorders provides the opportunity of studying the mechanism of oxidation of very long chain fatty acids. In this paper we report on such a study and also on the intracellular distribution in rat liver of the enzymes responsible for the activation of very long chain fatty acids. The results indicate that peroxisomes contain at least two fatty acid activating enzyme systems, one that activates long chain fatty acids such as palmitate and a second that is responsible for the activation of very long chain fatty acids, such as lignocerate and cerotate. The very long chain fatty acid synthetase is present not only in peroxisomes, but also, in agreement with Bhusnan et al. (20), in microsomes. Finally, we present evidence indicating that the peroxisomal very long chain acyl-CoA synthetase is deficient in X-linked adrenoleukodystrophy.

\section{Methods}

Cell culture conditions. Human skin fibroblasts from control individuals and patients with different peroxisomal disorders were cultured in $25 \mathrm{~cm}^{2}, 75 \mathrm{~cm}^{2}$, or $150 \mathrm{~cm}^{2}$ flasks containing $5 \mathrm{ml}, 15 \mathrm{ml}$, or $30 \mathrm{ml}$ HAM F-10 medium (Flow Laboratories, Irvine, Scotland), respectively, supplemented with $7.5 \%$ (vol/vol) fetal calf serum, $7.5 \%$ (vol/ vol) newborn calf serum, $3 \mathrm{mM}$ glutamine, $26.2 \mathrm{mM} \mathrm{NaHCO}_{3}, 100$ $\mathrm{U} / \mathrm{ml}$ penicillin, $100 \mu \mathrm{g} / \mathrm{ml}$ streptomycin, and $0.25 \mu \mathrm{g} / \mathrm{ml}$ fungizone in an atmosphere of 5\% (vol/vol) carbon dioxide in air. After the cells had reached confluency, the monolayer surface was washed twice with Hanks' balanced salt solution and an aliquot of $1.0,2.0$, or $3.0 \mathrm{ml}$ $0.25 \%(\mathrm{wt} / \mathrm{vol})$ trypsin in Hanks' balanced salt solution was added to each $25 \mathrm{~cm}^{2}, 50 \mathrm{~cm}^{2}$, or $75 \mathrm{~cm}^{2}$ culture flask, respectively. Upon detachment of the cells 5-10 ml HAM F-10 medium supplemented with fetal calf serum $(7.5 \% \mathrm{vol} / \mathrm{vol})$ and newborn calf serum $(7.5 \%$ $\mathrm{vol} / \mathrm{vol}$ ) was added and the content of each flask transferred to a plastic conical centrifuge tube. The cells were pelleted by centrifugation at room temperature (500 $\left.\mathrm{g}_{\mathrm{av}}, 5 \mathrm{~min}\right)$. After resuspension in Hanks' balanced salt solution, cells were centrifuged again and washed by suspension in phosphate-buffered saline. This washing step was repeated once more. The final cell pellet was taken up in a buffer containing $250 \mathrm{mM}$ sucrose plus $5 \mathrm{mM}$ morpholinopropane sulphonic acid (MOPS)-NaOH (final pH 7.4). Subsequently postnuclear supernatants were prepared by gentle homogenization of the cells using a Dounce homogenizer followed by centrifugation at $4^{\circ} \mathrm{C}$ to remove unbroken cells $\left(500 \mathrm{gav}_{\mathrm{av}}, 5 \mathrm{~min}\right)$. The postnuclear supernatants were kept on ice until use.

Measurement of fatty acid oxidation. Peroxisomal fatty acid $\beta$-oxidation was measured exactly as described for rat liver homogenates (21) using $\left[1-{ }^{14} \mathrm{C}\right]$ palmitic acid, $\left[1-{ }^{14} \mathrm{C}\right]$ lignoceric acid and $\left[1-{ }^{14} \mathrm{C}\right]-$ cerotic acid at a concentration of $10 \mu \mathrm{M}$ (final specific activity: 50 $\mathrm{mCi} / \mathrm{mmol}$ ). Reactions were started by addition of $20 \mu \mathrm{l}$ of fibroblast postnuclear supernatant at a final protein concentration of about $1 \mathrm{mg}$ protein $/ \mathrm{ml}$. After $60 \mathrm{~min}$ at $37^{\circ} \mathrm{C}$ reactions were terminated as described (21).

Measurement of fatty acid activation. The activity of palmitoylCoA synthetase, lignoceroyl-CoA synthetase and cerotoyl-CoA synthetase was measured as described for rat liver homogenates (21). Reactions were started by adding $20 \mu \mathrm{l}$ of fibroblast postnuclear supernatant in a final volume of $200 \mu \mathrm{l}$ at a protein concentration of $\sim 0.2 \mathrm{mg}$ protein $/ \mathrm{ml}$.

Preparation of rat liver subcellular fractions and equilibrium density gradient centrifugation. Rat livers from male Wistar rats (200-250 g) were finely minced and homogenized in a medium containing 250 $\mathrm{mM}$ sucrose, $2 \mathrm{mM}$ EDTA, $0.1 \%$ (vol/vol) ethanol and $2 \mathrm{mM}$ morpholinopropane sulphonic acid- $\mathrm{NaOH}$ (final pH 7.4). A fraction rich in peroxisomes was prepared by differential centrifugation according to standard procedures $(23,24)$. Subsequently, $0.5 \mathrm{ml}$ of this fraction was loaded on top of a preformed Metrizamide gradient $(20 \% \rightarrow 50 \%$, $\mathrm{wt} / \mathrm{vol})$. The gradient was formed by diffusion $\left(24 \mathrm{~h}, 4^{\circ} \mathrm{C}\right)$ after layering equal volumes $(0.9 \mathrm{ml})$ of $50 \%, 40 \%, 30 \%$, and $20 \%(\mathrm{wt} / \mathrm{vol}) \mathrm{Me}-$ trizamide in a buffer containing $2 \mathrm{mM}$ MOPS-NaOH plus $2 \mathrm{mM}$ EDTA (final pH 7.40). Centrifugation was carried out at $4^{\circ} \mathrm{C}$ for $5 \mathrm{~h}$ at $104,000 g_{a v}$ in an ultracentrifuge (L8-70, Beckman Instruments, Inc., Fullerton, CA) using a Ti-rotor (SW-55, Beckman Instruments, Inc.) (25). The gradient was carefully unloaded in the cold by making use of a hypodermic needle connected to a peristaltic pump. Fatty acyl-CoA synthetase measurements were carried out on freshly isolated fractions, whereas the other enzyme activities were measured after freezing.

Activity measurement of marker enzymes. Catalase (26), glutamate dehydrogenase (27), and NADPH: cytochrome $c$ oxidoreductase (25) were measured according to published procedures.

Patients. The patients studied in this paper were selected on the basis of established diagnoses. The Zellweger patients studied have been described elsewhere $(28,29)$. The infantile Refsum patients studied represent the three cases described by Saudubray and co-workers $(30,31)$. The neonatal adrenoleukodystrophy patients have also been described before $(32,33)$. The X-linked adrenoleukodystrophy patients showed the typical clinical and biochemical features described in the literature $(34,35)$. There was an accumulation of very long chain fatty acids, measured gaschromatographically as described by Moser and co-workers $(36,37)$ and expressed as $\mathrm{C} 26: 0 / \mathrm{C} 22: 0$ ratio in fibroblasts from the patients (see below).

\section{Results}

Table I shows the cofactor requirements for the peroxisomal $\beta$-oxidation of fatty acids in postnuclear supernatants of cultured skin fibroblasts. KCN was present to inhibit the mitochondrial $\beta$-oxidation system $(38,39)$. In fibroblasts, as in rat liver homogenates, the peroxisomal $\beta$-oxidation of palmitate (39), lignocerate (21), and cerotate is completely dependent upon the addition of ATP, coenzyme $\mathrm{A}, \mathrm{MgCl}_{2}$ and $\mathrm{NAD}^{+}$ (40). Omission of FAD had very little effect with either substrate.

We have previously shown that in rat liver homogenates the peroxisomal $\beta$-oxidation of palmitate $(\mathrm{C} 16: 0)$ and lignocerate (C24:0) show different dependencies upon the concentration of ATP, coenzyme $\mathrm{A}, \mathrm{Mg}^{2+}$ and $\mathrm{NAD}^{+}(21)$. Fig. 1 shows that this is also the case for human fibroblasts. As with rat liver homogenates this was especially apparent in the case

Table I. Cofactor Requirements for the Peroxisomal $\beta$-Oxidation of Palmitate, Lignocerate, and Cerotate in Postnuclear Supernatants of Fibroblasts

\begin{tabular}{lccc}
\hline & \multicolumn{2}{c}{ Activity (\% of maximum) } \\
\cline { 2 - 4 } $\begin{array}{l}\text { Omission from } \\
\text { incubation medium }\end{array}$ & Palmitate & Lignocerate & Cerotate \\
\hline None & $100 \pm 22$ & $100 \pm 18$ & $100 \pm 12$ \\
ATP & $3 \pm 1$ & $2 \pm 2$ & $3 \pm 2$ \\
CoA & $2 \pm 1$ & $4 \pm 2$ & $4 \pm 2$ \\
$\mathrm{MgCl}_{2}$ & $10 \pm 3$ & $13 \pm 3$ & $9 \pm 4$ \\
NAD & $5 \pm 2$ & $4 \pm 1$ & $4 \pm 2$ \\
FAD & $98 \pm 16$ & $96 \pm 12$ & $98 \pm 4$
\end{tabular}

Peroxisomal fatty acid $\beta$-oxidation was measured as described in Methods using palmitate, lignocerate, and cerotate as substrates. Values are means \pm SD for two to four different experiments. 


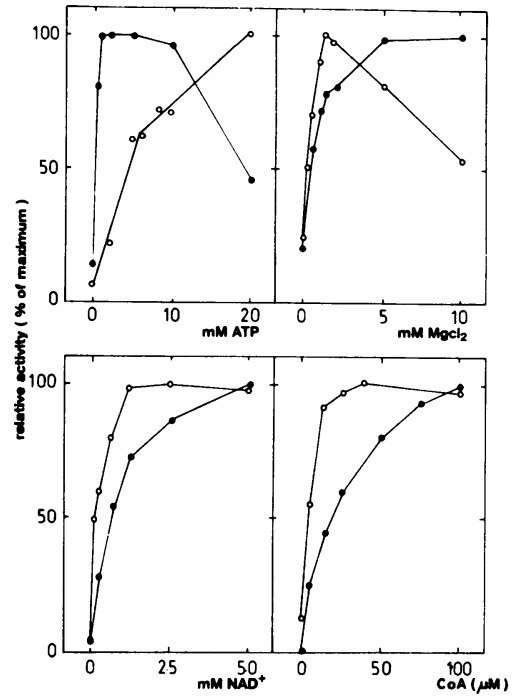

Figure 1. Dependence on the concentration of cofactors of the peroxisomal oxidation of [1$\left.{ }^{14} \mathrm{C}\right]$ lignocerate and [1${ }^{14} \mathrm{C}$ ]palmitate in postnuclear supernatants of cultured human skin fibroblasts from a control subject. When one of the cofactors was omitted, the others were kept constant at their standard concentrations (see text). Analogous results were obtained in two other experiments. $0,\left[1-{ }^{14} \mathrm{C}\right]$ lignocerate; $\bullet$, $\left[1-{ }^{14} \mathrm{C}\right]$ palmitate.

of ATP; the concentration required to give half-maximal rates of $\beta$-oxidation was $\sim 10 \mathrm{mM}$ in the case of lignocerate and $0.12 \mathrm{mM}$ in the case of palmitate.

Evidence for the presence of different fatty acid activating enzyme systems for palmitate and lignocerate in rat liver homogenates has recently been obtained by competition experiments (21). Similar results have now been obtained with fibroblast homogenates. Fig. 2 shows that the activation of palmitic acid to palmitoyl-CoA as measured in homogenates of cultured skin fibroblasts is not affected by addition of lignoceric acid or cerotic acid (C26:0), whereas the activation of lignoceric acid and cerotic acid to lignoceroyl-CoA and cerotoylCoA, respectively, is not affected by addition of palmitic acid.

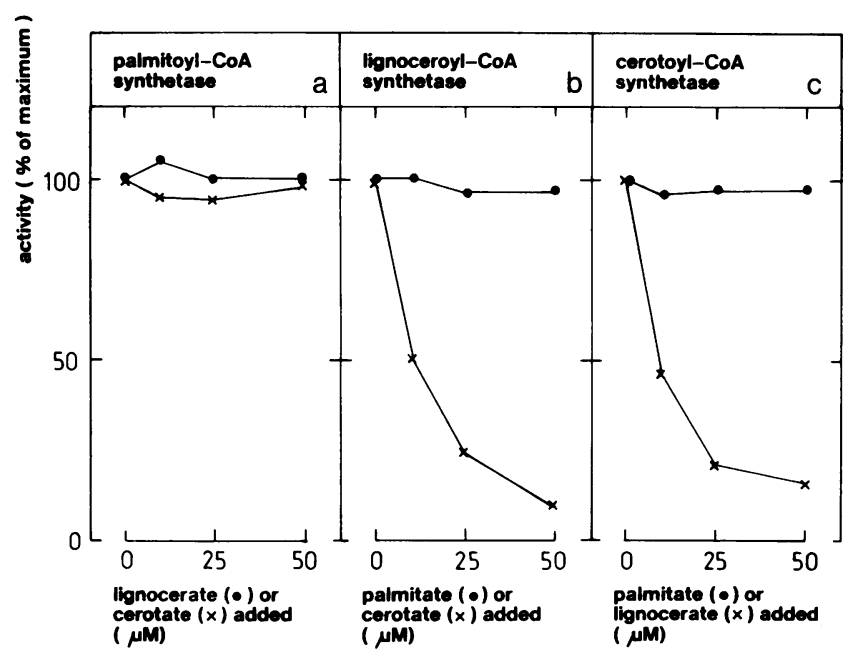

Figure 2. Effect of different concentrations of unlabeled fatty acids on the activation of $\left[1-{ }^{14} \mathrm{C}\right]$ palmitic acid, $\left[1-{ }^{14} \mathrm{C}\right]$ lignoceric acid and $[1-$ $\left.{ }^{14} \mathrm{C}\right]$ cerotic acid, respectively, in postnuclear supernatants of fibroblasts from a control subject. The activities of palmitoyl-CoA synthetase, lignoceroyl-CoA synthetase and cerotoyl-CoA synthetase were measured as described in Methods. In $A$ the substrate was $\left[1-{ }^{14} \mathrm{C}\right]-$ palmitic acid and different concentrations of lignoceric acid and cerotic acid were added. In $B$ the substrate was $\left[1-{ }^{14} \mathrm{C}\right]$ lignoceric acid and different concentrations of palmitic acid and cerotic acid were added. In $C$ the substrate was $\left[1-{ }^{14} \mathrm{C}\right]$ cerotic acid and different concentrations of palmitic acid and lignoceric acid were added.
On the other hand the activation of lignoceric acid is inhibited by cerotic acid and vice versa. Thus, as in rat liver, fibroblast homogenates contain at least two fatty acid activating enzyme systems, one able to activate palmitate and the other able to activate both lignocerate and cerotate.

Table II shows that there was an accumulation of very long chain fatty acids, as indicated by an elevated C26:0/C22:0 ratio, in fibroblasts from patients with the different peroxisomal disorders. Table II shows further that fibroblasts from patients with the Zellweger syndrome, infantile Refsum disease and neonatal adrenoleukodystrophy, genetic diseases characterized by a deficiency of peroxisomes $(9,32,41-44)$, are deficient in the ability to oxidize the very long chain fatty acids lignoceric acid and cerotic acid. Furthermore, the peroxisomal $\beta$-oxidation of palmitate, too, was found to be deficient in Zellweger fibroblasts.

Fibroblasts from patients with the X-linked form of adrenoleukodystrophy are able to $\beta$-oxidize palmitic acid at near normal rates but not lignoceric acid and cerotic acid (Table II). These findings, together with the observation by Hashmi and co-workers (22) and ourselves (unpublished results) that lignoceroyl-CoA and palmitoyl-CoA are oxidized at normal rates in fibroblasts from patients with X-linked adrenoleukodystrophy, suggest that the peroxisomal enzyme responsible for the activation of lignoceric acid and cerotic acid is deficient in $\mathrm{X}$-linked adrenoleukodystrophy. Measurement of very long chain fatty acyl-CoA synthetase activity with cerotic acid as substrate indicates that there is a small $(\sim 25 \%)$ but significant $(P<0.02)$ deficiency of this activity in fibroblasts from patients with X-linked adrenoleukodystrophy (Table III). This partial deficiency suggests that there is more than one enzyme able to catalyze the activation of very long chain fatty acids, and that only one of these enzymes is deficient in X-linked adrenoleukodystrophy. A partial deficiency is also found in the Zellweger syndrome (Table III; see Discussion).

We have therefore investigated the subcellular distribution of this enzyme activity. Since adequate methods to separate the different subcellular organelles present in cultured skin fibroblasts are not available at present, we have carried out fractionation experiments with rat liver using the procedure described by Wattiaux and co-workers (25). Fig. 3 shows the results of a typical experiment. A good separation between peroxisomes, mitochondria, and microsomes was obtained as indicated by the marker enzymes catalase, glutamate dehydrogenase and NADPH-cytochrome $c$ reductase, respectively. The results of Fig. 3 show that palmitoyl-CoA synthetase is present in peroxisomes, mitochondria and microsomes, in agreement with data from a number of authors (16-19). In contrast, however, very long chain fatty acyl-CoA synthetase showed a bimodal distribution of activity; the enzyme is present only in peroxisomes and microsomes and not in mitochondria. This conclusion was further substantiated by additional Metrizamide gradient centrifugation experiments, in which the mitochondrial $(M)$ and microsomal $(M c)$ fractions rather than the light mitochondrial $(M L)$ fraction were used (23).

\section{Discussion}

In Zellweger syndrome the deficient peroxisomal oxidation of palmitate, lignocerate and cerotate can be explained by the 
Table II. C26/C22-Very Long Chain Fatty Acids and the Peroxisomal Oxidation of Palmitic Acid, Lignoceric Acid, and Cerotic Acid in Fibroblasts from Controls and Patients with Different Peroxisomal Disorders

\begin{tabular}{|c|c|c|c|c|}
\hline \multirow[b]{2}{*}{ Fibroblast phenotype } & \multirow[b]{2}{*}{ C26/C22-ratio } & \multicolumn{3}{|c|}{ Peroxisomal fatty acid $\beta$-oxidation rate $(\mathrm{pmol} / \mathrm{min} \cdot \mathrm{mg})$} \\
\hline & & Palmitate & Lignocerate & Cerotate \\
\hline Controls & $\begin{array}{l}0.01-0.15 \\
(n=39)\end{array}$ & $\begin{array}{l}4.83 \pm 0.65 \\
(n=17)\end{array}$ & $\begin{array}{l}5.08 \pm 0.50 \\
(n=17)\end{array}$ & $\begin{array}{l}2.23 \pm 0.41 \\
(n=10)\end{array}$ \\
\hline Zellweger syndrome & $\begin{array}{l}0.21-0.98 \\
(n=17)\end{array}$ & $\begin{array}{l}0.78 \pm 0.23 \\
(n=6)\end{array}$ & $\begin{array}{l}0.40 \pm 0.31 \\
(n=10)\end{array}$ & $\begin{array}{l}0.18 \pm 0.10 \\
(n=6)\end{array}$ \\
\hline Infantile Refsum disease & $\begin{array}{l}0.21-1.05 \\
(n=3)\end{array}$ & ND & $\begin{array}{l}0.55 \pm 0.31 \\
(n=15)\end{array}$ & $\begin{array}{l}0.22 \pm 0.08 \\
(n=7)\end{array}$ \\
\hline Neonatal adrenoleukodystrophy & $\begin{array}{l}0.25-0.86 \\
(n=5)\end{array}$ & ND & $\begin{array}{l}0.28 \pm 0.20 \\
(n=18)\end{array}$ & $\begin{array}{l}0.19 \pm 0.05 \\
(n=6)\end{array}$ \\
\hline X-linked adrenoleukodystrophy & $\begin{array}{l}0.26-0.66 \\
(n=7)\end{array}$ & $\begin{array}{l}3.0 \pm 1.09 \\
(n=15)\end{array}$ & $\begin{array}{l}1.52 \pm 0.61 \\
(n=15)\end{array}$ & $\begin{array}{l}0.87 \pm 0.21 \\
(n=8)\end{array}$ \\
\hline
\end{tabular}

$\mathrm{C} 26 / \mathrm{C} 22$-very long chain fatty acids and rates of fatty acid $\beta$-oxidation were measured as described in Methods. Values represent the range (C26/C22-ratio) or mean $\pm \mathrm{SD}$ with the number of different experiments between parentheses.

deficiency of the three peroxisomal $\beta$-oxidation enzyme proteins as shown in liver by immunoblotting (45-47). Studies in cultured skin fibroblasts have shown that peroxisomal $\beta$-oxidation enzyme proteins are synthesized normally in Zellweger syndrome but are degraded rapidly due to the absence of peroxisomes (48). The same applies to infantile Refsum disease and neonatal adrenoleukodystrophy in which peroxisomes have also been shown to be strongly deficient in liver (32, $41-44)$ and cultured fibroblasts $(33,49)$.

Immunoblotting experiments carried out with liver from $\mathrm{X}$-linked adrenoleukodystrophy patients revealed that all three peroxisomal $\beta$-oxidation enzyme proteins were present in normal amounts (results not shown). These results do not exclude the possibility that one of the three proteins is catalytically inactive. However, the finding that the peroxisomal oxidation of palmitate is normal in X-linked adrenoleukodystrophy fibroblasts $(13,22$; and Table II) and liver (44) shows that the defect cannot be at the level of acyl-CoA oxidase,

Table III. Activity of Very Long Chain Fatty Acyl-CoA Synthetase in Fibroblasts from Controls and Patients with Zellweger Syndrome and X-Linked Adrenoleukodystrophy

\begin{tabular}{ll}
\hline Fibroblasts & Activity of cerotoyl-CoA synthetase \\
\hline & pmol/min $\cdot \mathrm{mg}$ protein \\
Controls & $29.7 \pm 2.2$ \\
& $(n=13)$ \\
X-linked adrenoleukodystrophy & $23.1 \pm 1.3^{*}$ \\
& $(n=15)$ \\
Zellweger syndrome & $22.3 \pm 1.6^{*}$ \\
& $(n=20)$
\end{tabular}

Very long chain fatty acyl-CoA synthetase activity was measured as described in Methods with $\left[1-{ }^{14} \mathrm{C}\right]$ cerotic acid as substrate. Results are expressed as mean \pm SEM with the number of experiments between parentheses. Statistical significance was calculated using Student's $t$ test $\left({ }^{*} P<0.02\right)$. bifunctional protein or peroxisomal 3-oxoacyl-CoA thiolase. The finding of Fig. 3 indicating that very long chain fatty acyl-CoA synthetase is present in microsomes and peroxisomes, at least in rat liver, together with the partial deficiency

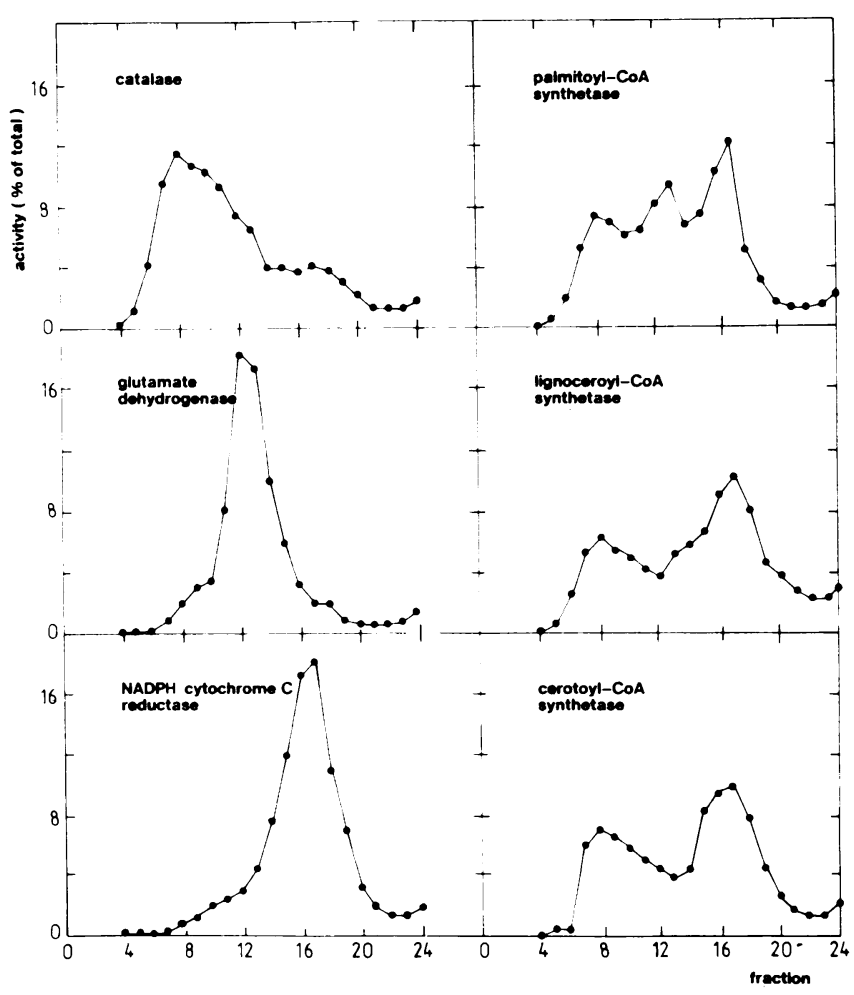

Figure 3. Distribution of palmitoyl-CoA synthetase, lignoceroyl-CoA synthetase and cerotoyl-CoA synthetase after equilibrium density gradient centrifugation of a light mitochondrial fraction. A fraction enriched in peroxisomes was prepared and subjected to density gradient centrifugation by the method of Wattiaux and co-workers (25) as described in Methods. Enzyme activity measurements were carried out as described in Methods. 
of this enzyme activity in X-linked adrenoleukodystrophy, suggests that it is the peroxisomal very long chain fatty acylCoA synthetase that is deficient in X-linked adrenoleukodystrophy, whereas the microsomal activity is normal. We are at present attempting to develop satisfactory cell fractionation techniques for fibroblasts in order to substantiate this conclusion by direct measurements. This conclusion is substantiated by the finding of Table III that a similar partial deficiency in very long fatty acyl-CoA synthetase activity is found in Zellweger fibroblasts. The partial deficiency in these cells must reflect the absence of peroxisomes; this would lead to a deficiency of peroxisomal (but not microsomal) very long chain fatty acyl-CoA synthetase, analogous to the deficiency of other peroxisomal membrane-bound enzymes such as dihydroxyacetone phosphate acyltransferase $(50,52)$. Our findings imply that there must be a tight coupling between the peroxisomal activation of very long chain fatty acids and their $\beta$-oxidation in the interior of the peroxisome; the microsomal very long chain fatty acyl-CoA synthetase although abundantly active in $\mathrm{X}$-linked adrenoleukodystrophy, is apparently not able to allow peroxisomal very long fatty acid $\beta$-oxidation to occur at normal rates.

\section{Acknowledgments}

We gratefully acknowledge Professor J. M. Saudubray, Dr. B. T. PollThé and especially Dr. A. B. Moser and Professor H. W. Moser for allowing us to study fibroblasts from their patients. The expert technical assistance of Gerrit-Jean Romeijn, Ellen Meyboom, Annie vandenPut, Paul Bentlage, Anneke Strijland, Desiree Saelman, and Betty Brouwer-Kelder is gratefully appreciated. Truus Klebach and Paula Zwaal are gratefully acknowledged for preparation of the manuscript.

This work was supported by grants from the Princess Beatrix Fund (The Hague, The Netherlands) and the Netherlands Organization for Pure Scientific Research (ZWO) under auspices of the Netherlands Foundation for Medical and Health Research (MEDIGON).

Note added in proof. Since the acceptance of our paper we have now obtained direct evidence for the suggestion made in Discussion that the defect in X-linked adrenoleukodystrophy is at the level of a deficient peroxisomal (but not microsomal) very long chain fatty acylCoA synthetase activity.

\section{References}

1. Mannaerts, G. P., and L. J. deBeer. 1981. $\beta$-Oxidation of fatty acids: relative contribution of mitochondria and peroxisomes. In Short-Term Regulation of Liver Metabolism. L. Hue, and G. Van de Werve, editors. Elsevier/North Holland, Amsterdam. 273-290.

2. Lazarow, P. B. 1982. Compartmentation of $\beta$-oxidation of fatty acids in peroxisomes. In Metabolic Compartmentation. H. Sies, editor. Academic Press, New York. 317-329.

3. Hajra, A. K. 1984. Biosynthesis of O-alkylglycerol ether lipids. In Ether-Lipids: Biochemical and Biomedical Aspects. J. K. Mangold, and F. Paltauf, editors. Academic Press, Inc., Orlando, FL. 85-106.

4. Björkhem, I. 1985. Mechanism of bile acid biosynthesis in mammalian liver. In Sterols and Bile Acids. $\mathrm{H}$. Danielsson, and $\mathrm{J}$. Sjövall, editors. Elsevier, Amsterdam, New York, Oxford. 231-278.

5. Kelley, R. I. 1983. The cerebro-hepato-renal syndrome of Zellweger, morphologic and metabolic aspects. Am. J. Med. Gen. 16:503517.

6. Goldfischer, S., and J. K. Reddy. 1984. Peroxisomes (microbodies) in cell pathology. Int. Rev. Exp. Pathol. 26:45-84.
7. Moser, H. W. 1986. Peroxisomal disorders. J. Pediatr. 108:8991.

8. Schutgens, R. B. H., H. S. A. Heymans, R. J. A. Wanders, H. vanden Bosch, and J. M. Tager. 1986. Peroxisomal disorders: A newly recognized group of genetic diseases. Eur. J. Pediatr. 144:430-440.

9. Goldfischer, S., C. L. Moore, A. B. Johnson, A. J. Spiro, M. P. Valsamis, H. K. Wisniewski, R. H. Ritch, W. T. Norton, I. Rapin, and L. M. Gartner. 1973. Peroxisomal and mitochondrial defects in cerebro-hepato-renal (Zellweger) syndrome. Science (Wash. DC). 227:6770.

10. Lazarow, P. B., and C. De Duve. 1976. A fatty acyl-CoA oxidizing system in rat liver peroxisomes; enhancement by clofibrate, a hypolipidemic drug. Proc. Natl. Acad. Sci. USA. 73:2043-2046.

11. Lazarow, P. B. 1978. Rat liver peroxisomes catalyze the $\beta$-oxidation of fatty acids. J. Biol. Chem. 253:1522-1528.

12. Bremer, J., and K. R. Norum. 1982. Metabolism of very long chain monounsaturated fatty acids (C22:1) and the adaptation to their presence in the diet. J. Lipid Res. 23:243-256.

13. Singh, I., A. B. Moser, S. Goldfischer, and H. W. Moser. 1984. Lignoceric acid is oxidized in the peroxisome: implications for the Zellweger cerebro-hepato-renal syndrome and adrenoleukodystrophy. Proc. Natl. Acad. Sci. USA. 81:4203-4207.

14. de Groot, P. H. E., H. R. Scholte, and W. C. Hülsmann. 1976. Fatty acid activation: specificity, localization and function. In Advances in Lipid Research. R. Paleotti, and D. Kritchevsky, editors. Academic Press, New York and London. 75-125.

15. Bremer, J., and H. Osmundsen. 1984. Fatty acid oxidation and its regulation. In Fatty Acid Metabolism and Its Regulation. S. Numa, editor. Elsevier, Amsterdam. 113-154.

16. Shindo, Y., and T. Hashimoto. 1978. Acyl-coenzyme A synthetase and fatty acid oxidation in rat liver peroxisomes. J. Biochem. (Tokyo). 84:1177-1181.

17. Krisans, S. K., R. M. Mortensen, and P. B. Lazarow. 1980. Acyl-CoA synthetase in rat liver peroxisomes. J. Biol. Chem. 255:9599-9607.

18. Mannaerts, G. P., P. Van Veldhoven, A. Van Broekhoven, G. Vande Broek, and L. J. DeBeer. 1982. Evidence that peroxisomal acyl-CoA synthetase is located at the cytoplasmic side of the peroxisomal membrane. Biochem. J. 204:17-23.

19. Miyazawa, S., T. Hashimoto, and S. Yokota. 1985. Identity of long-chain acyl-coenzyme A synthetase of microsomes, mitochondria, and peroxisomes in rat liver. J. Biochem. 98:723-733.

20. Bhusnan, A., R. P. Singh, and I. Singh. 1986. Characterization of rat brain microsomal acyl-coenzyme A ligases: different enzymes for the synthesis of palmitoyl-CoA and lignoceroyl-CoA. Arch. Biochem. Biophys. 246:374-380.

21. Wanders, R. J. A., C. W. T. van Roermund, M. J. A. van Wijland, R. B. H. Schutgens, A. W. Schram, H. vanden Bosch, and J. M. Tager. 1987. Studies on the peroxisomal oxidation of palmitate and lignocerate in rat liver. Biochim. Biophys. Acta. 919:21-25.

22. Hashmi, M., W. Stanley, and I. Singh. 1986. LignoceroylCoASH ligase: enzyme defect in fatty acid $\beta$-oxidation system in Xlinked adrenoleukodystrophy. FEBS (Fed. Eur. Biochem. Soc.) Lett. 196:247-250.

23. De Duve, C., B. C. Pressmann, R. Gianetto, R. Wattiaux, and F. Appelmans. 1955. Tissue fractionation studies: 6 . Intracellular distribution pattern of enzymes in rat-liver tissue. Biochem. J. 60:604617.

24. Leighton, F., B. Poole, H. Beaufay, P. Baudhuin, J. W. Coffey, S. Fowler, and C. de Duve. 1968. The large scale separation of peroxisomes, mitochondria, and lysosomes from the livers of rats injected with Triton WR-1339. Improved isolation procedures, automated analysis, biochemical and morphological properties of fractions. J. Cell Biol. 37:482-513.

25. Wattiaux, R., S. Wattiaux-de Coninck, M. F. Ronveau-Dupan, and F. Dubois. 1978. Isolation of rat liver lysosomes by isopycnic centrifugation in a Metrizamide gradient. J. Cell Biol. 78:349-368.

26. Wanders, R. J. A., C. W. T. van Roermund, C. T. de Vries, H. 
vanden Bosch, G. Schrakamp, J. M. Tager, A. W. Schram, and R. B. H. Schutgens. 1986. Peroxisomal $\beta$-oxidation of palmitoyl-CoA in human liver homogenates and its deficiency in the cerebro-hepatorenal (Zellweger) syndrome. Clin. Chim. Acta. 159:1-10.

27. Wanders, R. J. A., M. Kos, B. Roest, A. J. Meijer, G. Schrakamp, H. S. A. Heymans, W. H. H. Tegelaers, H. vanden Bosch, R. B. H. Schutgens, and J. M. Tager. 1984. Activity of peroxisomal enzymes and intracellular distribution of catalase in Zellweger syndrome. Biochem. Biophys. Res. Commun. 123:1054-1061.

28. Heymans, H. S. A., H. vanden Bosch, R. B. H. Schutgens, W. H. H. Tegelaerts, J.-U. Walther, J. Müller-Höcker, and P. Borst. 1984. Deficiency of plasmalogens in the cerebro-hepato-renal (Zellweger) syndrome. Eur. J. Pediatr. 142:10-15.

29. Wanders, R. J. A., W. Smit, H. S. A. Heymans, R. B. H. Schutgens, P. G. Barth, H. Schierbeek, G. P. A. Smit, R. Berger, H. Przyrembel, T. A. Eggelte, J. M. Tager, P. D. Maaswinkel-Mooy, A. C. B. Peters, L. A. H. Monnens, J. A. J. M. Bakkeren, J. M. F. Trijbels, E. J. P. Lommen, and N. Beganovic. 1987. Age-related accumulation of phytanic acid in plasma from patients with the cerebro-hepato-renal (Zellweger) syndrome. Clin. Chim. Acta. 166:45-56.

30. Scotto, J. M., M. Hadchouel, M. Odièvre, M.-H. Laudat, J.-M. Saudubray, O. Dulac, I. Beucler, and P. Bean. 1982. Infantile phytanic acid storage disease, a possible variant of Refsum's disease: three cases, including ultrastructural studies of the liver. J. Inher. Metab. Dis. 5:83-90.

31. Poll-Thé, B. T., J. M. Saudubray, M. Ogier, R. B. H. Schutgens, R. J. A. Wanders, G. Schrakamp, H. vanden Bosch, J. M. F. Trijbels, A. Poulos, H. W. Moser, J. van Eldere, and H. J. Eyssen. 1986. Infantile Refsum's disease: biochemical findings suggesting multiple peroxisomal dysfunction. J. Inher. Metab. Dis. 9:169-174.

32. Kelley, R. I., N. S. Datta, W. B. Dobyns, A. K. Hajra, A. B. Moser, M. J. Noetzel, E. H. Zackai, and H. W. Moser. 1986. Neonatal adrenoleukodystrophy: new cases, biochemical studies, and differentiation from Zellweger and related polydystrophy syndromes. Am. J. Med. Genet. 23:869-901.

33. Wanders, R. J. A., R. B. H. Schutgens, G. Schrakamp, J. M. Rager, H. vanden Bosch, A. B. Moser, and H. W. Moser. 1987. Neonatal adreno-leukodystrophy: impaired plasmalogen biosynthesis and peroxisomal $\beta$-oxidation due to a deficiency of catalase-containing particles (peroxisomes) in cultured skin fibroblasts. J. Neurol. Sci. 77:331-340

34. Moser, H. W., A. B. Moser, I. Singh, and B. P. O’Neill. 1984. Adrenoleukodystrophy: survey of 303 cases: biochemistry, diagnosis and therapy. Ann. Neurol. 16:628-641.

35. Powers, J. M. 1985. Adreno-leukodystrophy (adreno-testiculoleukomyelo-neuropathic complex). Clin. Neuropathol. 4:181-199.

36. Moser, H. W., A. B. Moser, N. Kanamura, J. Murphy, K. Suzuki, H. Schaumberg, and Y. Kishimoto. 1980. Adrenoleukodystrophy: elevated C26 fatty acid in cultured skin fibroblasts. Ann. Neurol. 7:542-549.

37. Moser, H. W., A. B. Moser, K. K. Frayer, W. Chen, J. D. Schulman, B. P. O'Neill, and Y. Kishimoto. 1981. Adrenoleukodystrophy: increased plasma content of saturated very long chain fatty acids. Neurology. 31:1241-1249.

38. Lazarow, P. B. 1981. Assay of peroxisomal $\beta$-oxidation of fatty acids. Methods Enzymol. 72:315-319.

39. Mannaerts, G. P., L. J. DeBeer, J. Thomas, and P. J. De Schepper. 1979. Mitochondrial and peroxisomal fatty acid oxidation in liver homogenates and isolated hepatocytes from control and clofibrate-treated rats. J. Biol. Chem. 254:4585-4595.

40. Singh, H., and A. Poulos. 1986. A comparative study of stearic acid and lignoceric acid oxidation by human skin fibroblasts. Arch. Biochem. Biophys. 250:171-179.

41. Ogier, H., F. Roels, A. Cornelis, B. T. Poll-Thé, J. M. Scotto, M. Odièvre, and J. M. Saudubray. 1985. Absence of hepatic peroxisomes in a case of infantile Refsum's disease. Scand. J. Clin. Lab. Invest. 45:767-768.

42. Roels, F., A. Cornelis, B. T. Poll-Thé, P. Aubourg, H. Ogier, J. M. Scotto, and J. M. Saudubray. 1986. Hepatic peroxisomes are deficient in infantile Refsum disease. A cytochemical study of 4 cases. Am. J. Med. Genet. 25:257-271.

43. Partin, J. S., and A. J. McAdams. 1983. Absence of peroxisomes in neonatal onset adrenoleukodystrophy. Pediatr. Res. 17:294. (Abstr.)

44. Goldfischer, S., J. Collins, I. Rapin, B. Coltoff-Schiller, C.-H. Chang, M. Nigro, V. H. Black, N. B. Javitt, H. W. Moser, and P. B. Lazarow. 1985. Peroxisomal defects in neonatal onset and X-linked adrenoleukodystrophy. Science (Wash. DC). 227:67-70.

45. Tager, J. M., W. A. Ten Harmsen van de Beek, R. J. A. Wanders, T. Hashimoto, H. S. A. Heymans, H. vanden Bosch, R. B. H. Schutgens, and A. W. Schram. 1985. Peroxisomal $\beta$-oxidation enzyme proteins in the Zellweger syndrome. Biochem. Biophys. Res. Commun. 126:1269-1275.

46. Lazarow, P. B., V. Black, H. Shio, Y. Fujiki, A. K. Hajra, N. S. Datta, B. S. Banguru, and J. Dancis. 1985. Zellweger syndrome: biochemical and morphological studies on two patients treated with clofibrate. Pediatr. Res. 19:1356-1364.

47. Suzuki, Y., T. Orri, M. Mori, M. Tatibana, and T. Hashimoto. 1986. Deficient activities and proteins of peroxisomal $\beta$-oxidation enzymes in infants with Zellweger syndrome. Clin. Chim. Acta. 156:191-196.

48. Schram, A. W., A. Strijland, T. Hashimoto, R. J. A. Wanders, R. B. H. Schutgens, H. vanden Bosch, and J. M. Tager. 1986. Biosynthesis and maturation of peroxisomal $\beta$-oxidation enzymes in fibroblasts in relation to the Zellweger syndrome and infantile Refsum disease. Proc. Natl. Acad. Sci. USA. 83:6156-6158.

49. Wanders, R. J. A., R. B. H. Schutgens, G. Schrakamp, H. vanden Bosch, J. M. Tager, A. W. Schram, T. Hashimoto, B. T. PollThé, and J. M. Saudubray. 1986. Infantile Refsum disease: deficiency of catalase-containing particles (peroxisomes), alkyldihydroxyacetone phosphate synthase and peroxisomal $\beta$-oxidation enzyme proteins. Eur. J. Pediatr. 145:172-175.

50. Datta, N. S., G. N. Wilson, and A. K. Hajra. 1984. Deficiency of enzymes catalyzing the biosynthesis of glycerol-ether lipids in Zellweger syndrome: a new category of metabolic diseases involving the absence of peroxisomes. N. Engl. J. Med. 311:1080-1083.

51. Schrakamp, G., C. F. P. Rooseboom, R. B. H. Schutgens, R. J. A. Wanders, H. S. A. Heymans, J. M. Tager, and H. Vanden Bosch. 1985. Alkyldihydroxyacetone phosphate synthase in human fibroblasts and its deficiency in Zellweger syndrome. J. Lipid Res. 26:867-873.

52. Schutgens, R. B. H., G. J. Romeijn, R. J. A. Wanders, H. Van den Bosch, G. Schrakamp, and H. S. A. Heymans. 1984. Deficiency of acyl-CoA: dihydroxyacetone phosphate acyltransferase in patients with Zellweger (cerebro-hepato-renal) syndrome. Biochem. Biophys. Res. Commun. 120:179-184. 